\title{
Lack of association between human leukocyte antigen polymorphisms rs9277535 and rs7453920 and chronic hepatitis $B$ in a Brazilian population
}

\author{
V.R.Z.B. Pereira ${ }^{1,2,3}$, J.M. Wolf ${ }^{3,4}$, G.Z. Stumm ${ }^{1}$, T.R. Boeira ${ }^{3,4}$, J. Galvan ${ }^{2}$, \\ D. Simon ${ }^{3}$ and V.R. Lunge ${ }^{3,4}$ \\ ${ }^{1}$ Universidade de Caxias do Sul, Caxias do Sul, RS, Brasil \\ ${ }^{2}$ Prefeitura Municipal de Caxias do Sul, Serviço Municipal de Infectologia, \\ Caxias do Sul, RS, Brasil \\ ${ }^{3}$ Programa de Pós-Graduação em Biologia Celular e Molecular Aplicada à Saúde, \\ Universidade Luterana do Brasil, Canoas, RS, Brasil \\ ${ }^{4}$ Laboratório de Diagnóstico Molecular, Universidade Luterana do Brasil, \\ Canoas, RS, Brasil \\ Corresponding author: J.M. Wolf \\ E-mail: jonasmwolf@gmail.com \\ Genet. Mol. Res. 16 (2): gmr16029565 \\ Received December 6, 2017 \\ Accepted May 8, 2017 \\ Published May 31, 2017 \\ DOI http://dx.doi.org/10.4238/gmr16029565
}

Copyright $(2017$ The Authors. This is an open-access article distributed under the terms of the Creative Commons Attribution ShareAlike (CC BY-SA) 4.0 License.

ABSTRACT. Hepatitis B virus (HBV) infection is a serious public
health problem worldwide. The progression of the disease depends on
several host and viral factors and may result in fulminant hepatitis (very
rare), acute hepatitis with spontaneous clearance, and chronic hepatitis
B infection. Previous studies demonstrated that variations in the human
leukocyte antigen (HLA) class II (HLA-DPB1 and $H L A-D Q B 2$ genes)
are related to the chronic HBV infection. This study aimed to investigate
the association of two single nucleotide polymorphism (SNPs), one in
the $H L A-D P B 1$ (rs 9277535 ) and one in the $H L A$ - $D Q B 2$ (rs7453920),
with chronic hepatitis B infection in a southern Brazilian sample. This
case-control study included $260 \mathrm{HBV}$ patients attended in a Specialized

Genetics and Molecular Research 16 (2): gmr16029565 
Center for Health in Caxias do Sul (Brazil) between 2014 and 2016. The same number of controls (matching for age, gender, and ethnicity) was obtained in a University Hospital in the same city and period. Blood samples were collected and genomic DNA was extracted. Genotyping were performed by real-time Taqman PCR method. Odds ratios with $95 \%$ confidence intervals and significance level of $5 \%(\mathrm{P}<0.05)$ were calculated. Allele frequencies in the SNP rs9277535 were $72.6 \%$ for A and $27.4 \%$ for $\mathrm{G}$ nucleotides in cases and $75.0 \%$ for $\mathrm{A}$ and $25.0 \%$ for $\mathrm{G}$ in controls. Allele frequencies in the SNP rs 7453920 were of $25.7 \%$ for $\mathrm{A}$ and $74.3 \%$ for $\mathrm{G}$ in cases and $28.8 \%$ for $\mathrm{A}$ and $71.2 \%$ for $\mathrm{G}$ in controls. No statistically significant association was found between both SNPs and chronic hepatitis B $(\mathrm{P}>0.05)$.

Key words: Hepatitis B virus; Single nucleotide polymorphism; Chronic hepatitis B; HLA antigens

\section{INTRODUCTION}

Hepatitis B virus (HBV) infection is a serious public health problem worldwide (Tang et al., 2014). Approximately 240 million of the world population has chronic HBV infection, which is the leading cause of chronic hepatitis (WHO - World Health Organization, 2014). Moreover, HBV chronic disease can progress to hepatic dysfunction, cirrhosis, and hepatocellular carcinoma (Zeng et al., 2014; Poh et al., 2015). More than 600,000 people die every year due to these clinical complications of HBV infection (Nelson et al., 2014; Niederau, 2014). Most of the HBV-infected people live in countries with high endemicity in East Asia and sub-Saharan Africa (WHO - World Health Organization, 2016). In South America, endemicity ranges from intermediate (e.g., southern Brazil and Ecuador) to high (e.g., North Brazil and Peru) (Roman et al., 2014). In Brazil, 120,343 cases of hepatitis B were reported in 2012. South Brazil region represents around 31.6\% of the total case notifications in the country (Brasil, 2012).

HBV transmission frequently occurs by contact with infected blood and body fluids (Zeng et al., 2014). The course of the disease depends on several host and viral factors and may result in fulminant hepatitis $(<1 \%)$, acute hepatitis with spontaneous clearance, and chronic hepatitis B infection. The progression of hepatitis B infection to a chronic disease is not usual (less than 10\%) when infection occurs in an adult, but it is common (around 90\%) with the HBV transmission in the birth or childhood (WHO - World Health Organization, 2016). This high progression rate in infants is associated with an immune system not yet fully consolidated (Tang et al., 2014).

Human leukocyte antigen (HLA) complex helps the immune system to detect antigens of bacterium and virus particles. HLA complex acts on the antigen processing and presentation in the humoral or cellular responses (Mohamadkhani et al., 2015). HLA biomolecule classes I and II are expressed on antigen-presenting cells (APC), acting in antigen presentation to T lymphocytes. This immune response mediated by T lymphocytes is essential in resolving HBV infections (Mohamadkhani et al., 2015; Wang et al., 2016). HLA complex comprises genes located basically on chromosome 6 . The peptides that comprise the HLA class I complex are encoded by the genes $H L A-A,-B,-C$, and $-D$. Moreover, HLA class II complex consist of $\alpha$

Genetics and Molecular Research 16 (2): gmr16029565 
and $\beta$ chains that are organized into heterodimers. $H L A-D P B 1$ and $H L A-D Q B 2$ genes encode $\beta$ subunits 1 and 2, respectively (McCanlies et al., 2003; Shiina et al., 2004).

Genetic polymorphisms in the HLA classes I and II were well investigated and have been strongly associated with HBV persistence and progression to chronic hepatitis B infection (Singh et al., 2007; Mbarek et al., 2011; Jiang et al., 2014; Zeng et al., 2014). Recent genome-wide association studies (GWAS) have demonstrated two single nucleotide polymorphisms (SNPs) located in the genes $H L A-D P B 1$ (rs9277535, A/G) and HLA-DQB2 (rs7453920, A/G). Both are associated with the persistence of HBV infection, mainly in Asian populations (Kamatani et al., 2009; Mbarek et al., 2011; Wong et al., 2013; Al-Qahtani et al., 2014). These SNPs result in an A to G transition in two different gene regions: rs9277535 in the 3'-untranslated region (3'-UTR) of the HLA-DPB1 gene and rs7453920 in the intron 1 of the HLA-DQB2 gene. These SNPs may affect the regulation of gene expression and stability of mRNA (Mohamadkhani et al., 2015) with the G allele conferring a higher risk to HBV chronic infection (Mbarek et al., 2011; O'Brien et al., 2011; Thomas et al., 2012; Hu et al., 2013; Mohamadkhani et al., 2015). The aim of this study was to investigate possible associations of these two SNPs with chronic hepatitis B in a population sample in southern Brazil.

\section{MATERIAL AND METHODS}

\section{Patients and controls}

Adult HBV patients and controls were from the city of Caxias do Sul, Rio Grande do Sul State, South Brazil. The sample size was estimated as previously described (Lwanga and Lemeshow, 1991), with statistical power of $80 \%$, significance at the $5 \%$ level (two-tailed test), average exposure frequency of SNPs in controls of 50.7\% (Ensembl Genome Browser, 2016), and an odds ratio (OR) of 1.8 at a $95 \%$ confidence interval (CI). Therefore, the total sample was initially calculated to include 191 cases and the same number of controls. More 138 samples (26.5\%) were added for potential confounders, totaling 260 cases and 260 controls. The case group was composed of individuals routinely attended in the Specialized Center for Health in the city of Caxias do Sul (Centro Especializado em Saúde - CES) from September 2014 to March 2016. They were visiting the service for periodic exams and/or treatment for chronic hepatitis B (all were HBsAg-positive). Controls were obtained by convenience sampling at a University Hospital (Hospital Geral) in the same city and period. All control individuals were negative for HBsAg and they did not have primary sclerosing cholangitis, Wilson's disease, hepatitis $\mathrm{C}$ virus (HCV), cirrhosis, acquired immunodeficiency syndrome, hypertension, cancer, hepatitis, and autoimmune diseases (criteria for exclusion). The samples from both groups were matched (for age, gender, and ethnicity) as previously described (Pereira et al., 2017).

\section{SNP genotyping}

Blood samples were collected in tubes with EDTA anticoagulant and stored at $-70^{\circ} \mathrm{C}$ for further molecular analysis. Genomic DNA was extracted by silica adsorption method as described by Boom et al. (1990). SNPs rs9277535 and rs7453920 were detected by commercial real-time TaqMan polymerase chain reaction (PCR) assays with reference codes C_29715274_20 and C_27015605_10 (Applied Biosystems, Foster City, CA, USA). The reactions were carried out in a StepOne Plus ${ }^{\mathrm{TM}}$ platform (Applied Biosystems) with cycling and

Genetics and Molecular Research 16 (2): gmr16029565 
temperature conditions according to the manufacturer. Allelic discrimination was performed using the StepOne ${ }^{\mathrm{TM}}$ software (Version 2.3, Applied Biosystems). Controls were used in all experiments aimed at the reliability of technical procedures.

\section{Statistical analysis}

The data were analyzed using the SPSS (Statistical Package for Social Sciences, version 17.0, Chicago, IL, USA) software. Genotype and allele frequencies were determined by direct counting and Hardy-Weinberg equilibrium was evaluated by the chi-square test. Statistical Power calculation was performed using the software Epi Info ${ }^{\mathrm{TM}}$ version 7.1.5.2. In bivariate analysis, the OR at $95 \% \mathrm{CI}$ was estimated in order to detect the possible association of the SNPs with chronic hepatitis B. All estimates were bilateral with a significance level of $5 \%(\mathrm{P}<0.05)$.

\section{RESULTS}

Socio-demographic information and clinical history of HBV infection were obtained from all participants of the survey $(\mathrm{N}=520)$. The overall average age of the $260 \mathrm{HBV}$ patients was $47.62 \pm 12.22$ years and there were $143(55 \%)$ males and $229(88 \%)$ self-defined whites.

All the 520 samples were analyzed for the SNPs rs9277535 and rs7453920, but only 420 samples ( 210 cases and respective controls) could be effectively genotyped. Table 1 shows the genotypes and alleles observed for SNPs rs9277535 and rs7453920 in cases and controls. In a general analysis for the SNP rs 9277535 , the overall genotypes frequencies were $55.2 \%$ for $\mathrm{A} / \mathrm{A}, 37.1 \%$ for $\mathrm{A} / \mathrm{G}$, and $7.6 \%$ for $\mathrm{G} / \mathrm{G}$. The allele frequencies for this SNP were $73.8 \%$ for $\mathrm{A}$ and $26.2 \%$ for G nucleotides. The SNP rs 7453920 presented genotype frequencies of $8.3 \%$ for $\mathrm{A} / \mathrm{A}, 37.9 \%$ for $\mathrm{A} / \mathrm{G}$, and $53.8 \%$ for $\mathrm{G} / \mathrm{G}$ and allele frequencies were $27.3 \%$ for $\mathrm{A}$ and $72.7 \%$ for $\mathrm{G}$ nucleotides (Table 1).

\begin{tabular}{|c|c|c|c|c|c|c|c|c|}
\hline \multirow{2}{*}{ Polymorphisms } & \multicolumn{2}{|c|}{ Cases $(\mathrm{N}=210)$} & \multicolumn{2}{|c|}{ Controls $(\mathrm{N}=210)$} & \multicolumn{2}{|c|}{ Total $(\mathrm{N}=420)$} & \multirow{2}{*}{ OR $(95 \% \mathrm{CI})$} & \multirow{2}{*}{$\mathrm{P}$} \\
\hline & $\mathrm{N}$ & $\%$ & $\mathrm{~N}$ & $\%$ & $\mathrm{~N}$ & $\%$ & & \\
\hline & \multicolumn{6}{|c|}{$H L A-D P B 1$ (rs9277535) } & & \\
\hline \multicolumn{9}{|l|}{ Genotypes } \\
\hline $\mathrm{A} / \mathrm{A}$ & 111 & 52.9 & 121 & 57.6 & 232 & 55.2 & 1.00 & - \\
\hline $\mathrm{A} / \mathrm{G}$ & 83 & 39.5 & 73 & 34.8 & 156 & 37.1 & $1.24(0.83-1.86)$ & 0.300 \\
\hline $\mathrm{G} / \mathrm{G}$ & 16 & 7.6 & 16 & 7.6 & 32 & 7.6 & $1.09(0.52-2.28)$ & 0.819 \\
\hline \multicolumn{9}{|l|}{ Alleles } \\
\hline A & 305 & 72.6 & 315 & 75.0 & 620 & 73.8 & 1.00 & - \\
\hline \multirow[t]{2}{*}{ G } & 115 & 27.4 & 105 & 25.0 & 220 & 26.2 & $1.13(0.83-1.54)$ & 0.432 \\
\hline & \multicolumn{6}{|c|}{$H L A-D Q B 2($ rs 7453920$)$} & & \\
\hline \multicolumn{9}{|l|}{ Genotypes } \\
\hline $\mathrm{A} / \mathrm{A}$ & 18 & 8.6 & 17 & 8.1 & 35 & 8.3 & 1.00 & - \\
\hline $\mathrm{A} / \mathrm{G}$ & 72 & 34.3 & 87 & 41.4 & 159 & 37.9 & $0.78(0.38-1.63)$ & 0.509 \\
\hline $\mathrm{G} / \mathrm{G}$ & 120 & 57.1 & 106 & 50.5 & 226 & 53.8 & $1.07(0.53-2.18)$ & 0.854 \\
\hline \multicolumn{9}{|l|}{ Alleles } \\
\hline A & 108 & 25.7 & 121 & 28.8 & 229 & 27.3 & 1.00 & - \\
\hline G & 312 & 74.3 & 299 & 71.2 & 611 & 72.7 & $1.17(0.86-1.58)$ & 0.314 \\
\hline
\end{tabular}

The genotype frequencies in the case group for the SNP rs 9277535 were $52.9 \%$ (A/A), 39.5\% (A/G), and 7.6\% (G/G), while allele frequencies were $72.6 \%(\mathrm{~A})$ and $27.4 \%$

Genetics and Molecular Research 16 (2): gmr16029565 
(G). In the control group, genotype frequencies were $57.6 \%(\mathrm{~A} / \mathrm{A}), 34.8 \%(\mathrm{~A} / \mathrm{G})$, and $7.6 \%$ $(\mathrm{G} / \mathrm{G})$, while allele frequencies were $75.0 \%(\mathrm{~A})$ and $25.0 \%(\mathrm{G})$. The SNP rs 7453920 presented genotype frequencies in the case group of $8.6 \%(\mathrm{~A} / \mathrm{A}), 34.3 \%(\mathrm{~A} / \mathrm{G})$, and $57.1 \%(\mathrm{G} / \mathrm{G})$ and allele frequencies of $25.7 \%(\mathrm{~A})$ and $74.3 \%(\mathrm{G})$. In the control group, genotype frequencies of $8.1 \%(\mathrm{~A} / \mathrm{A}), 41.4 \%(\mathrm{~A} / \mathrm{G})$, and $50.5 \%(\mathrm{G} / \mathrm{G})$ and allele frequencies of $28.8 \%(\mathrm{~A})$ and $71.2 \%$ (G) were observed. The frequencies of the genotypes and alleles were in agreement with Hardy-Weinberg equilibrium $(\mathrm{P}>0.05)$ for both SNPs evaluated in cases and controls. No associations were observed between the $\mathrm{G}$ alleles for SNP rs9277535 $(\mathrm{OR}=1.13 ; 95 \% \mathrm{CI}=$ $0.83-1.54 ; \mathrm{P}=0.432)$ and $\mathrm{rs} 7453920(\mathrm{OR}=1.17 ; 95 \% \mathrm{CI}=0.86-1.58 ; \mathrm{P}=0.314)$ in relation to chronic hepatitis $\mathrm{B}$. In addition, none of the genotypes evaluated demonstrated any statistically significant association with this disease $(\mathrm{P}>0.05)$ (Table 1).

\section{DISCUSSION}

This study investigated the associations between HBV chronic infection and two SNPs, one in $H L A-D P B 1$ (rs9277535) and one in HLA-DQB2 (rs7453920), in a sample of South Brazilian patients. There is enough evidence that these SNPs play important roles in the persistence of the HBV infection (Mohamadkhani et al., 2015). However, the complete mechanism of HBV infection and progression to hepatitis B are not fully understood (Kim et al., 2013). In general, host genetic background influences the immune processing of APC cells, necessary for an effective immune response. SNPs rs9277535 and rs7453920 affect the gene expression of the $H L A-D P B 1$ and $H L A-D Q B 2$ molecules and they were demonstrated to be important in the recognition and processing of viral particles (Mohamadkhani et al., 2015).

In this scenario, the possible associations between SNPs located in the HLA-DPB1 (rs9277535) and $H L A-D Q B 2$ (rs7453920) genes with the HBV chronic infection were analyzed in a population from southern Brazil. However, no statistically significant association was found $(\mathrm{P}>0.05$ ). World studies demonstrated that the HLA-DPB1 (rs9277535) polymorphism is often found in Asians $(\approx 0.61)$ and less frequent in other populations, such as Europeans $(\approx 0.27)$, South Americans $(\approx 0.29)$, and Africans $(\approx 0.19)$. The HLA-DQB2 (rs7453920) polymorphism is often found in Asia $(\approx 0.87)$, Europe $(\approx 0.62)$, South America $(\approx 0.73)$, and Africa $(\approx 0.70)$. In this sense, the frequency of variant alleles $(26.2 \%$ for rs 9277535 and $72.7 \%$ for rs7453920) observed in the present study were consistent with previous observations in South America (Ensembl Genome Browser, 2016).

Several studies, especially analyzing Asian samples, found association between the SNP rs9277535 and chronic HBV infection (Kamatani et al., 2009; Lau et al., 2011; Mbarek et al., 2011; Png et al., 2011; Nishida et al., 2012; Yan et al., 2012; Kim et al., 2013; Seto et al., 2013; Al-Qahtani et al., 2014; Chang et al., 2014; Liao et al., 2014; Pan et al., 2014; He et al., 2015; Yu et al., 2015). Additionally, the study conducted by Thomas et al. (2012) found an association between the SNP rs9277535 and the elimination rate of HBV in patients EuroAmerican and African-Americans $(\mathrm{P}=0.0001)$. However, Vermehren et al. (2012) did not find an association of this SNP with chronic hepatitis B in Caucasians. In the study conducted by O'Brien et al. (2011), the SNP rs9277535 was associated with a reduction in HLA-DPB1 gene expression in European patients. In Asian studies, the SNP rs7453920 was associated with the immune response to HBV (Mbarek et al., 2011; Al-Qahtani et al., 2014; Liao et al., 2014; He et al., 2015). However, no studies have associated this SNP in samples from other regions of the world.

Genetics and Molecular Research 16 (2): gmr16029565 
This study has some limitations. First, the double or triple pairing was not performed and, second, it was not possible to analyze SNPs in all samples $(\mathrm{N}=520)$ due to technical laboratory restrictions. Anyway, the findings seem to demonstrate clearly the lack of association of these SNPs with chronic hepatitis B. This is very important to the understanding of this issue in a population from South Brazil with higher rates than the average (Menegol and Spilki, 2014). Further research with larger samples can generate more detailed knowledge of the frequencies of the SNPs evaluated in this study, as well as the contribution of these for chronic hepatitis B.

\section{CONCLUSION}

In this study, no associations were observed between the SNPs (rs9277535/rs7453920) and progression to chronic hepatitis B. Our data suggest that SNPs in HLA-DPB1 (rs9277535) and HLA-DQB2 (rs7453920) genes do not influence the chronicity of hepatitis $\mathrm{B}$ in the analyzed sample.

\section{Conflicts of interests}

The authors declare no conflict of interest.

\section{ACKNOWLEDGMENTS}

Research supported by Universidade Luterana do Brasil (ULBRA) and SIMBIOS Biotecnologia.

\section{REFERENCES}

Al-Qahtani AA, Al-Anazi MR, Abdo AA, Sanai FM, et al. (2014). Association between HLA variations and chronic hepatitis B virus infection in Saudi Arabian patients. PLoS One 9: e80445. https://doi.org/10.1371/journal.pone.0080445

Brasil (2012). Ministério da Saúde. Boletim Epidemiológico das Hepatites Virais. Ano III - $\mathrm{n}^{\circ}$ 1. Brasília. Available at [http://www.aids.gov.br/sites/default/files/anexos/publicacao/2012/51820/boletim_epidemiol_gico_hepatites_ virais_2012_ve_12026.pdf].

Boom R, Sol CJ, Salimans MM, Jansen CL, et al. (1990). Rapid and simple method for purification of nucleic acids. $J$. Clin. Microbiol. 28: 495-503.

Chang SW, Fann CS, Su WH, Wang YC, et al. (2014). A genome-wide association study on chronic HBV infection and its clinical progression in male Han-Taiwanese. PLoS One 9: e99724. https://doi.org/10.1371/journal.pone.0099724

Ensembl Genome Browser (2016). 1000 Genomes Project Phase 3 Allele Frequencies. Available at [http://www.ensembl. org/index.html].

He D, Tao S, Guo S, Li M, et al. (2015). Interaction of TLR-IFN and HLA polymorphisms on susceptibility of chronic HBV infection in Southwest Han Chinese. Liver Int. 35: 1941-1949. https://doi.org/10.1111/liv.12756

Hu Z, Liu Y, Zhai X, Dai J, et al. (2013). New loci associated with chronic hepatitis B virus infection in Han Chinese. Nat. Genet. 45: 1499-1503. https://doi.org/10.1038/ng.2809

Jiang X, Ma Y, Cui W and Li MD (2014). Association of variants in HLA-DP on chromosome 6 with chronic hepatitis B virus infection and related phenotypes. Amino Acids 46: 1819-1826. https://doi.org/10.1007/s00726-014-1767-2

Kamatani Y, Wattanapokayakit S, Ochi H, Kawaguchi T, et al. (2009). A genome-wide association study identifies variants in the HLA-DP locus associated with chronic hepatitis B in Asians. Nat. Genet. 41: 591-595. https://doi.org/10.1038/ng.348

Kim YJ, Kim HY, Lee JH, Yu SJ, et al. (2013). A genome-wide association study identified new variants associated with the risk of chronic hepatitis B. Hum. Mol. Genet. 22: 4233-4238. https://doi.org/10.1093/hmg/ddt266

Lau KC, Lam CW, Law CY, Lai ST, et al. (2011). Non-invasive screening of HLA-DPA1 and HLA-DPB1 alleles for persistent hepatitis B virus infection: susceptibility for vertical transmission and toward a personalized approach for

Genetics and Molecular Research 16 (2): gmr16029565 
vaccination and treatment. Clin. Chim. Acta 412: 952-957. https://doi.org/10.1016/j.cca.2011.01.030

Liao Y, Cai B, Li Y, Chen J, et al. (2014). Association of HLA-DP/DQ and STAT4 polymorphisms with HBV infection outcomes and a mini meta-analysis. PLoS One 9: e111677. https://doi.org/10.1371/journal.pone.0111677

Lwanga S and Lemeshow S (1991). Sample size determination in health studies: a practical manual. Geneva, World Health Organization.

Mbarek H, Ochi H, Urabe Y, Kumar V, et al. (2011). A genome-wide association study of chronic hepatitis B identified novel risk locus in a Japanese population. Hum. Mol. Genet. 20: 3884-3892. https://doi.org/10.1093/hmg/ddr301

McCanlies EC, Kreiss K, Andrew M and Weston A (2003). HLA-DPB1 and chronic beryllium disease: a HuGE review. Am. J. Epidemiol. 157: 388-398. https://doi.org/10.1093/aje/kwg001

Menegol D and Spilki FR (2014). Seroprevalence of Hepatitis B and C markers at the population level in the municipality of Caxias do Sul, southern Brazil. Braz. J. Microbiol. 44: 1237-1240. https://doi.org/10.1590/S151783822014005000013

Mohamadkhani A, Katoonizadeh A and Poustchi H (2015). Immune-Regulatory Events in the Clearance of HBsAg in Chronic Hepatitis B: Focuses on HLA-DP. Middle East J. Dig. Dis. 7: 5-13.

Nelson NP, Jamieson DJ and Murphy TV (2014). Prevention of Perinatal Hepatitis B Virus Transmission. J. Pediatric Infect. Dis. Soc. 3 (Suppl 1): S7-S12. https://doi.org/10.1093/jpids/piu064

Niederau C (2014). Chronic hepatitis B in 2014: great therapeutic progress, large diagnostic deficit. World J. Gastroenterol. 20: 11595-11617. https://doi.org/10.3748/wjg.v20.i33.11595

Nishida N, Sawai H, Matsuura K, Sugiyama M, et al. (2012). Genome-wide association study confirming association of HLA-DP with protection against chronic hepatitis B and viral clearance in Japanese and Korean. PLoS One 7: e39175. https://doi.org/10.1371/journal.pone.0039175

O'Brien TR, Kohaar I, Pfeiffer RM, Maeder D, et al. (2011). Risk alleles for chronic hepatitis B are associated with decreased mRNA expression of HLA-DPA1 and HLA-DPB1 in normal human liver. Genes Immun. 12: 428-433. https://doi.org/10.1038/gene.2011.11

Pan L, Zhang L, Zhang W, Wu X, et al. (2014). A genome-wide association study identifies polymorphisms in the HLADR region associated with non-response to hepatitis B vaccination in Chinese Han populations. Hum. Mol. Genet. 23: 2210-2219. https://doi.org/10.1093/hmg/ddt586

Pereira VRZB, Wolf JM, Luz C, Stumm G, et al. (2017). Risk factors for hepatitis B transmission in South Brazil. Mem. Inst. Oswaldo Cruz [Epub ahead of print].

Png E, Thalamuthu A, Ong RT, Snippe H, et al. (2011). A genome-wide association study of hepatitis B vaccine response in an Indonesian population reveals multiple independent risk variants in the HLA region. Hum. Mol. Genet. 20: 3893-3898. https://doi.org/10.1093/hmg/ddr302

Poh Z, Goh BB, Chang PE and Tan CK (2015). Rates of cirrhosis and hepatocellular carcinoma in chronic hepatitis B and the role of surveillance: a 10-year follow-up of 673 patients. Eur. J. Gastroenterol. Hepatol. 27: 638-643. https://doi. org/10.1097/MEG.0000000000000341

Roman S, Jose-Abrego A, Fierro NA, Escobedo-Melendez G, et al. (2014). Hepatitis B virus infection in Latin America: a genomic medicine approach. World J. Gastroenterol. 20: 7181-7196. https://doi.org/10.3748/wjg.v20.i23.7181

Seto WK, Wong DK, Kopaniszen M, Proitsi P, et al. (2013). HLA-DP and IL28B polymorphisms: influence of host genome on hepatitis B surface antigen seroclearance in chronic hepatitis B. Clin. Infect. Dis. 56: 1695-1703. https:// doi.org/10.1093/cid/cit121

Shiina T, Inoko H and Kulski JK (2004). An update of the HLA genomic region, locus information and disease associations: 2004. Tissue Antigens 64: 631-649. https://doi.org/10.1111/j.1399-0039.2004.00327.x

Singh R, Kaul R, Kaul A and Khan K (2007). A comparative review of HLA associations with hepatitis B and C viral infections across global populations. World J. Gastroenterol. 13: 1770-1787. https://doi.org/10.3748/wjg.v13.i12.1770

Tang CM, Yau TO and Yu J (2014). Management of chronic hepatitis B infection: current treatment guidelines, challenges, and new developments. World J. Gastroenterol. 20: 6262-6278. https://doi.org/10.3748/wjg.v20.i20.6262

Thomas R, Thio CL, Apps R, Qi Y, et al. (2012). A novel variant marking HLA-DP expression levels predicts recovery from hepatitis B virus infection. J. Virol. 86: 6979-6985. https://doi.org/10.1128/JVI.00406-12

Vermehren J, Lötsch J, Susser S, Wicker S, et al. (2012). A common HLA-DPA1 variant is associated with hepatitis B virus infection but fails to distinguish active from inactive Caucasian carriers. PLoS One 7: e32605. https://doi. org/10.1371/journal.pone.0032605

Wang L, Zou ZQ and Wang K (2016). Clinical Relevance of HLA Gene Variants in HBV Infection. J. Immunol. Res. 2016: 9069375. https://doi.org/10.1155/2016/9069375

WHO - World Health Organization (2014). Guidelines for the prevention, care and treatment of persons with chronic hepatitis B infection, 2014. Available at [http://apps.who.int/iris/bitstream/10665/154590/1/9789241549059_eng.pdf].

Genetics and Molecular Research 16 (2): gmr16029565 
WHO - World Health Organization (2016). Available at [http://www.who.int/mediacentre/factsheets/fs204/en/index.html]. Wong DK, Watanabe T, Tanaka Y, Seto WK, et al. (2013). Role of HLA-DP polymorphisms on chronicity and disease activity of hepatitis B infection in Southern Chinese. PLoS One 8: e66920. https://doi.org/10.1371/journal. pone.0066920

Yan Z, Tan S, Dan Y, Sun X, et al. (2012). Relationship between HLA-DP gene polymorphisms and clearance of chronic hepatitis B virus infections: case-control study and meta-analysis. Infect. Genet. Evol. 12: 1222-1228. https://doi. org/10.1016/j.meegid.2012.03.026

Yu L, Cheng YJ, Cheng ML, Yao YM, et al. (2015). Quantitative assessment of common genetic variations in HLA-DP with hepatitis B virus infection, clearance and hepatocellular carcinoma development. Sci. Rep. 5: 14933. https://doi. org/10.1038/srep14933

Zeng LY, Lian JS, Chen JY, Jia HY, et al. (2014). Hepatitis B surface antigen levels during natural history of chronic hepatitis B: a Chinese perspective study. World J. Gastroenterol. 20: 9178-9184.

Genetics and Molecular Research 16 (2): gmr16029565 